\title{
ANALYSIS OF VEHICLES DYNAMIC PROPERTIES FROM THE POINT OF VIEW OF PASSENGER COMFORT
}

The passenger ride comfort can be assessed via the indexes of comfort i.e. via the indirect method in accordance with the European standard ENV 12299: 1999 or 2006. This method is based on the values of accelerations knowledge in the analysed places of vehicle body. The signal of accelerations is filtered and weighted with functions that take into account the sensitivity of human body to the vehicle body vibrations in reference directions. The signal is statistically assessed and the ride comfort indexes for floor, sitting or standing positions are evaluated. The accelerations coming into the assessment of ride comfort indexes can be obtained from measurements or as results of a computer simulation. The paper deals with the accelerations analysis and their influence on the final comfort index.

Key words: ride comfort index, computer simulation, kinematic excitation, nonlinear computational model

\section{Introduction}

The passenger ride comfort presents a very important and up-to date issue. The passenger ride comfort is the basic presupposition of a commercial benefit for cars and railway vehicles operators and a criterion of attractiveness for passengers of this transport form. The exploitation of computer simulation and detail computer analyses of measured experimental data allow a decrease in experimental tests size. Expenses for the development of new vehicles construction and re-construction are being decreased as well.

The aim of the authors was to apply the assessment procedures of passenger ride comfort in a rail vehicle through the "indirect" method (via the numerical processing of accelerations values). This is the way how to obtain the final value of the comfort index. The advantage of the method is that the analysis takes into account only the vehicle/track couple quality and the results are not influenced by subjective feelings of passengers. The analysis of the flexible binding member parameters and their influence on ride comfort indexes must be taken into account as well.

\section{Passenger comfort}

Comfort is a complex sensation produced during the application of oscillations and/or inertia forces, via the whole-body transmission caused by vehicle-frame movements [1, 12]. It is defined and measured through comfort indexes as:

- Mean comfort: a mean feeling, continuously adjusted, as evaluated through a measurement following the procedures for comfort index $N_{M V}$ and indexes $N_{V A}$ and $N_{V D}$.
- Comfort on Curve Transition: discomfort, due to a perceived curve entry or reverse transition, quantified by the recommended procedure indicated as comfort index $P_{C T}$.

- Comfort on Discrete Events: discomfort, due to a perceived transient oscillation on a straight track, curves and curve transitions, qualified by the recommended procedure indicated as comfort index $P_{D E}$.

Comfort indexes assessment procedures utilised for the computation are introduced by authors in detail in [4].

\section{Accelerations in vehicle acting on passengers}

The accelerations values necessary for "comfort for passengers" assessment may be obtained in various ways. They are mainly based on a direct, in a vehicle body, measurement and on the computer simulation results. We obtained the necessary accelerations information with the help of computer simulations of vehicle under the running conditions.

\section{Vehicle model parameters}

We used the geometric, mass and flexible binding parameters in accordance with known passengers wagon ERRI for a model analysis. This dummy parameters set is commonly used as a specimen example of a simulation analysis in the MSC.ADAMS computational system.

The model was processed with the "DELTA" programme system. The programme system DELTA works on the base of the

\footnotetext{
* Tomas Lack, Juraj Gerlici

Faculty of Mechanical Engineering, University of Zilina, Slovakia, E-mail: tomas.lack@fstroj.uniza.sk
} 


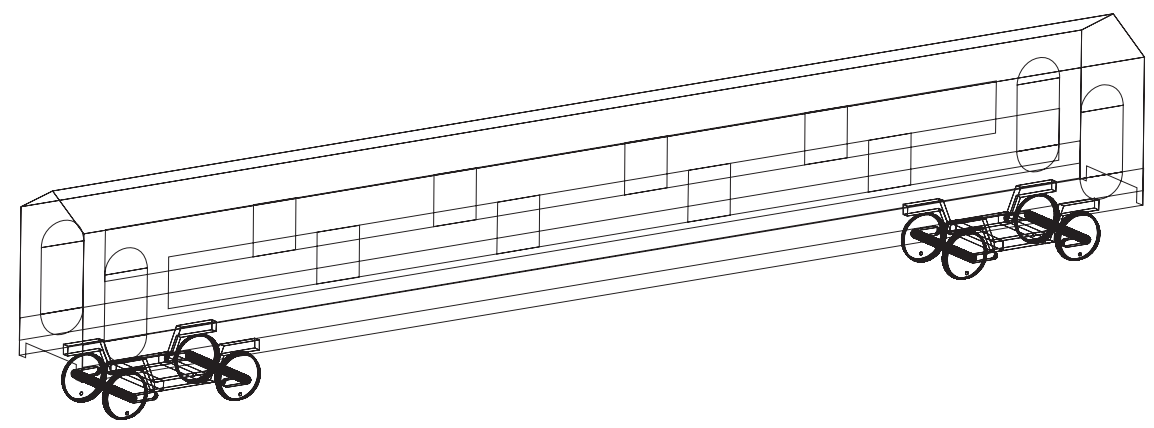

Fig.1 3D model of vehicle (MSC.ADAMS/Rail [10])

finite element method theory. Because of special model parameters setting (in accordance with the ADAMS system), it behaves like the system of no-mass frames. We can proclaim that from the point of view of commercial programme packages features, the DELTA programme with its working features is closer to the FEM (ANSYS - the Transient analysis part) system than to MBS (ADAMS) system. It is possible to take into account the flexibility of modelled bodies when the real stiffness and cross-sections parameters are known and set as input parameters for a computation. The programme was built in the environment of the programme language DELPHI for an operation in the environment of the MS Windows XP operational system. It was designed on the base of an opened component system. The programme DELTA allows performing static and dynamic mechanical systems analyses. An input of data of a vehicle mechanical system is carried out with the help of node points and elements: a linear spring, nonlinear spring, a beam, a linear damper, nonlinear damper and mass point.

\section{Boundary and starting conditions:}

- prescribed displacements, velocities and accelerations of nodes;

- prescribed revolutions, angular velocities and angular accelerations of nodes;

- prescribed forces and torques acting in nodal points;

- prescribed accelerations acting on a vehicle.

Methods for dynamics solution:

- the eigenfrequencies and eigenvectors assessment with the help of Jacobi's rotation method;

- a response analysis evoked by harmonic excitation;

- a direct solution of a model oscillation in the time domain with the following methods: the differential method, the HHT- method, the method of linear accelerations, the Newmark method, the Wilson- method and the Crank-Nicolson method.

Equations solution methods (solver) are Frontal elimination and L-U decomposition.

The otput is graphical and textual. The eigenfrequencies and eigenvectors assessment was performed with the Jacobi's rotation method. A response analysis from harmonic excitation and a direct solution of model oscillation were performed in the time domain.

The Newmark modified method was used for the direct solution in the time domain. This method is known as the "HHT-

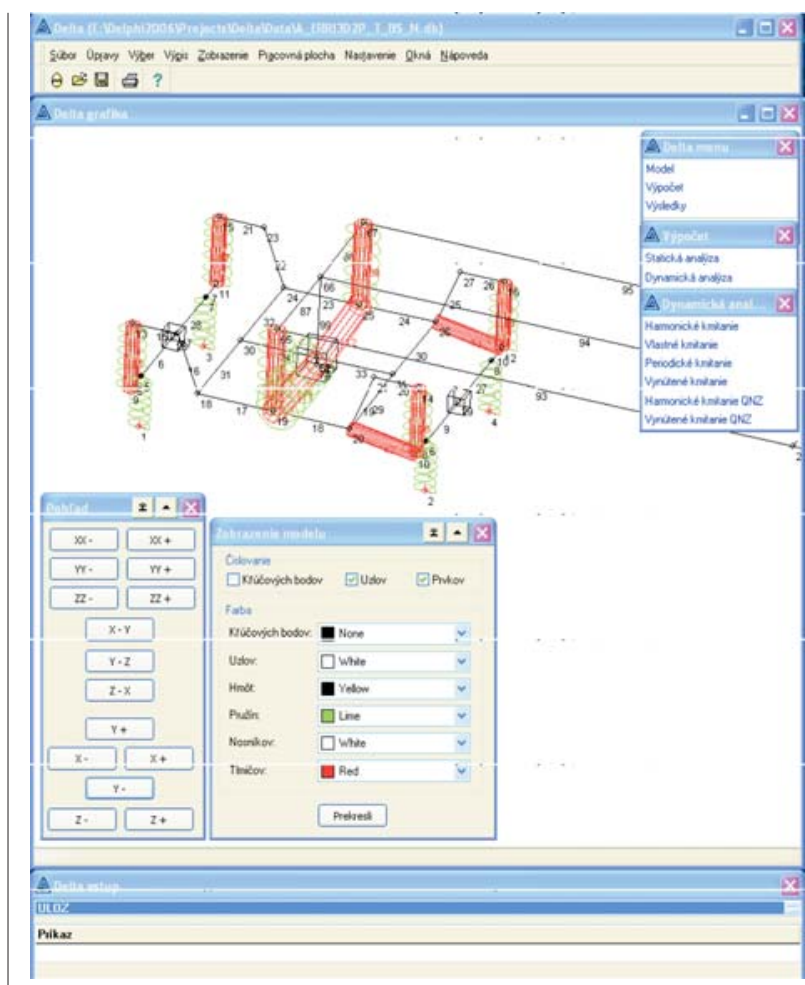

Fig. 2 The DELTA programme main screen when the menu are opened

method". The method was modified for the solution of dynamic systems with nonlinear members. The usage of this method has been recently very relevant in the field of technical computations performance. The main advantage is in the decrease of time which is necessary for computing. The linear algebraic equations system was computed with the help of the Frontal elimination method. This method is suitable for big systems of linear equation solution, known in connection with numerical analyses based on the Finite element method theory. The computational model was built up from 80 nodal points and 132 elements. The model has 456 degrees of freedom, the computational front width is 66 . All the amount of track sections is 257 , which represents the 1285 seconds of vehicle running. 

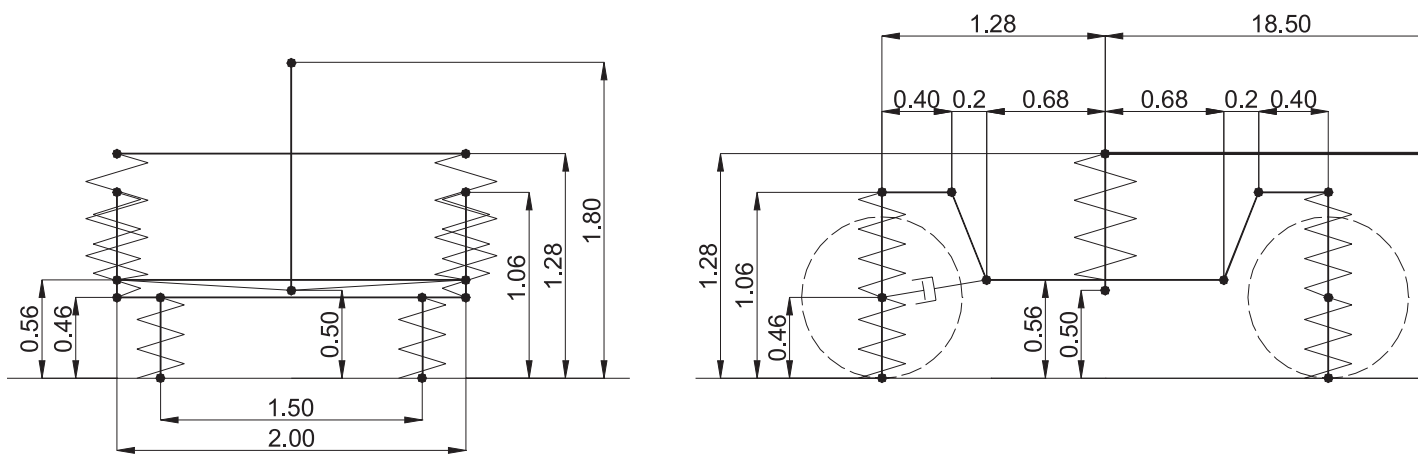

Fig. 3 Geometrical parameters of chosen dynamic model of vehicle in accordance with [10]

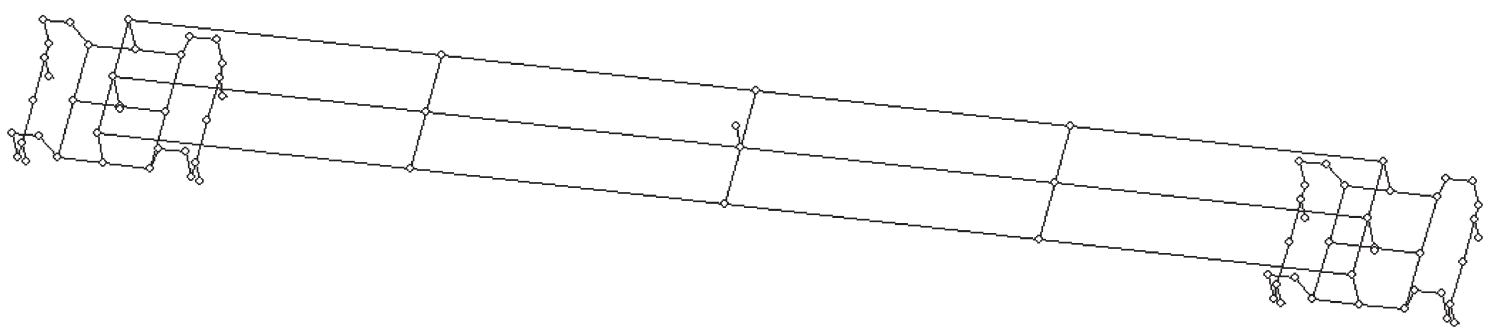

Fig.4 The whole vehicle model (DELTA)

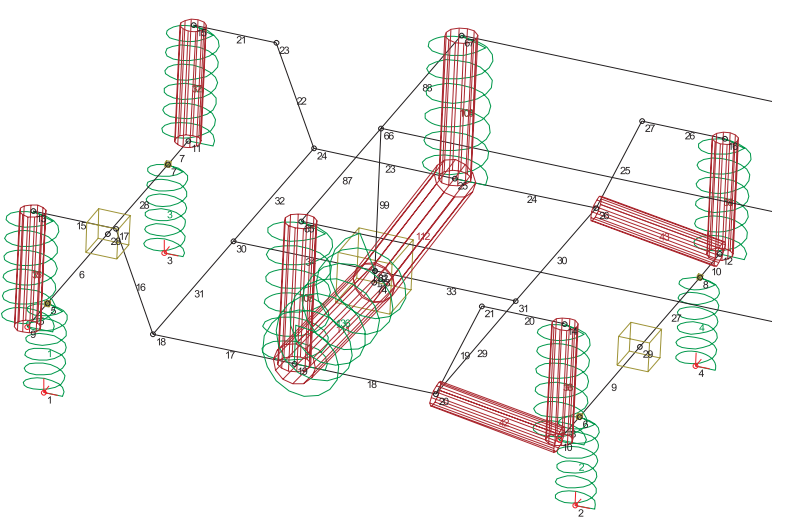

Fig.5 The rear bogie with depicted consctruction elements, 2. bogie (DELTA)

The list of some important eigenfrequencies is processed in the following table. The eigenvectors due to these frequencies representation is in the following figures as well.

Other eigenfrequencies and to them pertaining eigenvectors are not important from the point of this analysis. The reason is that they represent deformations of "rigid" structures of the model (bogies frames or a vehicle body). The frequencies are out of analysis limits in the time domain where s, which corresponds to the $200 \mathrm{~Hz}$ frequency.
The dominant oscillation shapes specification

Tab. 1

\begin{tabular}{|c|c|c|l|}
\hline $\begin{array}{c}\text { Conse- } \\
\text { cutive } \\
\text { number }\end{array}$ & $\begin{array}{c}\text { Eigen angle } \\
\text { velocity } \\
\text { Omega } \\
{[1 / \mathrm{rad}]}\end{array}$ & $\begin{array}{c}\text { Eigen- } \\
\text { frequency } \\
f[\mathrm{~Hz}]\end{array}$ & \multicolumn{1}{|c|}{$\begin{array}{c}\text { Dominant form } \\
\text { of eigenvector }\end{array}$} \\
\hline 1. & 3.8846 & 0.618 & Lower swaying \\
\hline 2. & 4.1525 & 0.661 & Longitudinal oscillation \\
\hline 3. & 5.602 & 0.892 & Yawing \\
\hline 4. & 5.8127 & 0.925 & Upper swaying \\
\hline 5. & 6.2382 & 0.993 & Bouncing \\
\hline 6. & 7.345 & 1.169 & Pitching \\
\hline 7. & 28.5857 & 4.55 & $\begin{array}{l}\text { Swaying of individual bogies } \\
\text { in opposed directions }\end{array}$ \\
\hline 8. & 28.7195 & 4.571 & $\begin{array}{l}\text { Swaying of individual bogies } \\
\text { in a concurrent way }\end{array}$ \\
\hline 9. & 29.3639 & 4.673 & $\begin{array}{l}\text { Pitching of individual bogies } \\
\text { in opposed directions }\end{array}$ \\
\hline 10. & 29.4082 & 4.68 & $\begin{array}{l}\text { Pitching of individual bogies } \\
\text { in a concurrent way }\end{array}$ \\
\hline
\end{tabular}

\section{Verification of nonlinear model}

The vehicle in a real operation has its special parameters. In general it is characterised by its own properties. For a reliable vehicle 


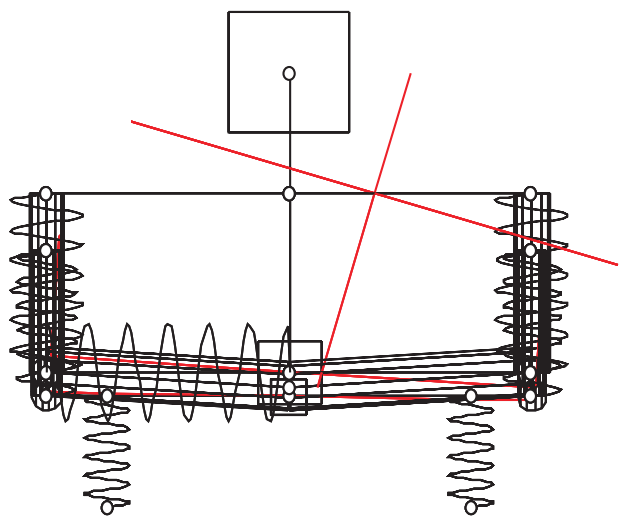

Fig. 6 1. eigenvector when the eigenfrequency is $0.618 \mathrm{~Hz}$

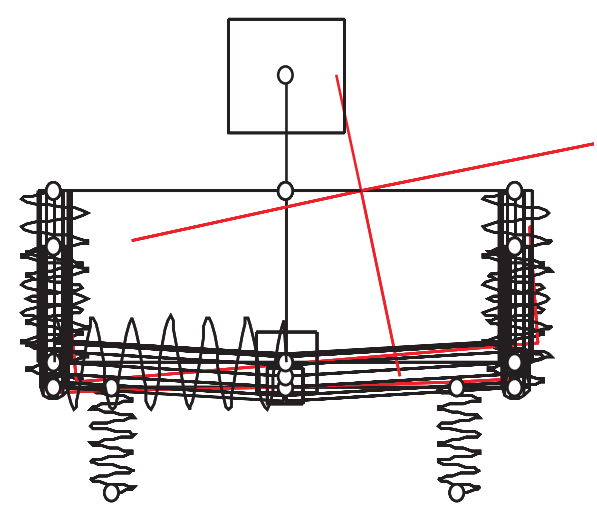

Fig. 9 4. eigenvector when the eigenfrequency is $0.925 \mathrm{~Hz}$

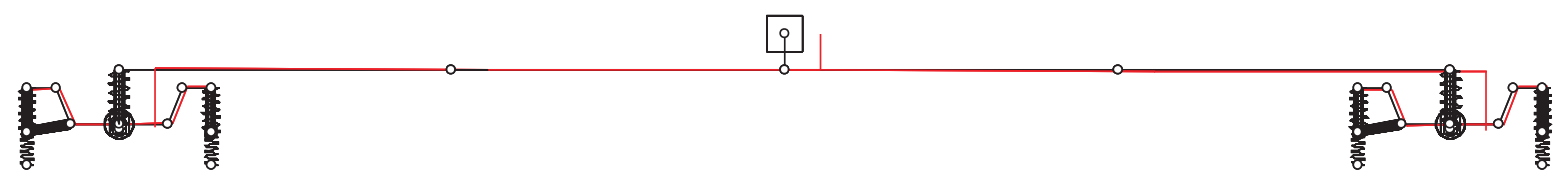

Fig. 7 2. eigenvector when the eigenfrequency is $0.661 \mathrm{~Hz}$

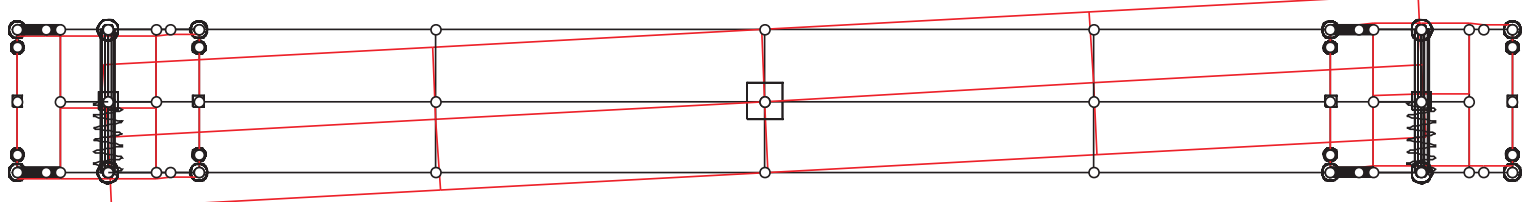

Fig. 8 3. eigenvector when the eigenfrequency is $0.892 \mathrm{~Hz}$

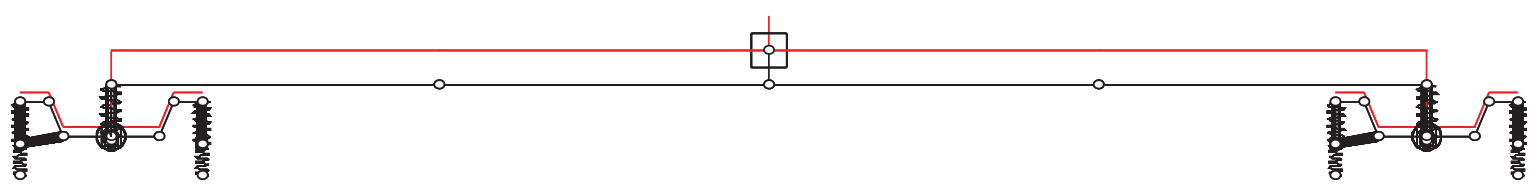

Fig. 10 5. eigenvector when the eigenfrequency is $0.993 \mathrm{~Hz}$

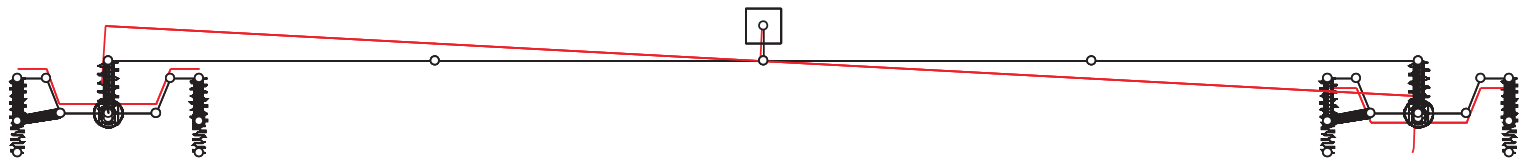

Fig. 11 6. eigenvector when the eigenfrequency is $1.169 \mathrm{~Hz}$

$\prod_{0}^{0}$
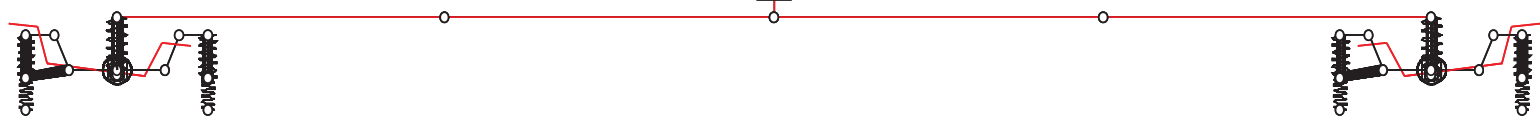

Fig. 12 9. eigenvector when the eigenfrequency is $4.673 \mathrm{~Hz}$ - pitching of individual bogies in opposed directions 


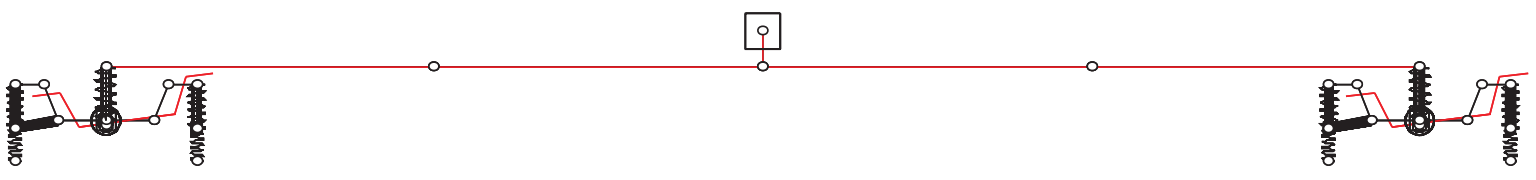

Fig. 13 10. eigenvector when the eigenfrequency is $4.68 \mathrm{~Hz}$ - pitching of individual bogies in a concurrent way

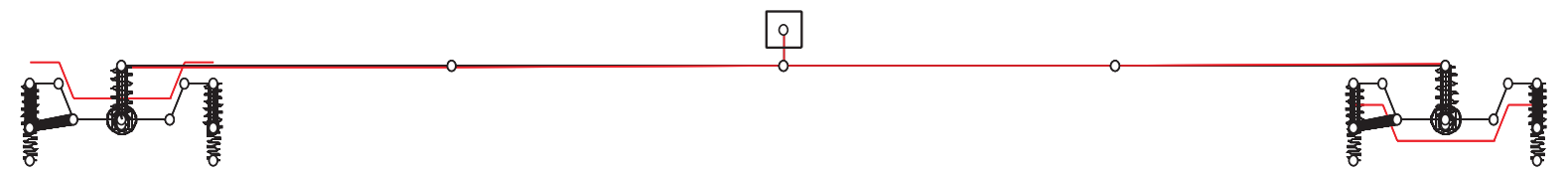

Fig. 14 12. eigenvector when the eigenfrequency is i $5.465 \mathrm{~Hz}$ - bouncing of individual bogies in opposed directions

properties assessment and behaviour judgement we are to verify the trustworthiness of its computational model.

1. The computation with linear members in the time and frequency domains - provides a rough outline.

2. Non-liner members do not have features of members (in any point of the characteristics) when a deformation is increasing or a deformation velocity is increasing. It may happen that the internal force is decreasing or is maintained on an initial internal force value level.

3. Energetic balance:

$$
\begin{array}{ll} 
& \Delta \Pi=\Pi(q+\delta q)-\Pi(q)=\delta q^{T} \cdot(F-R)+ \\
& +\frac{1}{2} \delta q^{T} \cdot K_{t} \cdot \delta q=\delta \Pi+\delta^{2} \Pi \\
& \Delta \Pi \doteq \delta^{2} \Pi=\frac{1}{2} \delta q^{T} \cdot K_{t} \cdot \delta q \\
\Pi & - \text { is the energy } \\
q & - \text { is the vector of generalised movements } \\
K & - \text { is the tangential stiffness matrix } \\
F & - \text { is the vector of internal forces } \\
R & - \text { is the vector of external loads }
\end{array}
$$

For all the vectors is valid

$$
\delta q \text { is } \Delta \Pi>0
$$

4. The parameters of stability choice of the HHT method an amplitude decreasing ratio $\gamma \rightarrow(0 \div 1 / 3)=0.15$

$\alpha=\frac{1}{4}(1+\gamma)^{2} ; \delta=\frac{1}{2}+\gamma ; \alpha_{f}=\gamma ; \alpha_{m} \leq \alpha_{f}$

5. A vehicle model - an examination whether a computational model with its parameters and excitation parameters corresponds to the reality and whether the results of computations are valid.
In our case we will perform the model verification with the help of a comparison of theoretic characteristics of flexible bindings members with the corresponding values of forces obtained from computations.

We put the spring of high stiffness in a serial way into the model. The spring in the place of a nonlinear member evaluates the current value of an internal force due to velocity, or change of position of the nonlinear member boundary points. In an ideal case the depicted result is the same as the theoretically requested characteristic curve.

We analysed the dynamic properties of a "common model" vehicle with overtaken parameters [10]. We were looking for the acceleration evaluation on the vehicle with the purpose of defined kinematic excitation and when the acceleration acts due to the track geometry. No classic rail/wheel contact model was used for the analysis in spite of the fact that the authors are interested in various types of contact model evaluation.

\section{Modelling of excitation}

\subsection{Acquired track parameters from measurement}

The input parameters for the excitation of a vehicle mechanical system are: given (measured) geometric layout deviations $Y_{L}$, $Y_{P}, Z_{L}, Z_{P}$, vehicle velocity $V$, cant $U$, track curvature $K$, track $s$, time $t, w(x)$ is a track gauge that is evaluated according to the following relation:

$$
w=1435+Y_{L}(x)-Y_{P}(x)
$$

- A vehicle is influenced by these accelerations:

$$
\begin{aligned}
& a_{x}=\frac{d v}{d t}, \\
& a_{y}=a_{D} \cdot \cos \alpha,
\end{aligned}
$$




$$
a_{\mathrm{Z}}=a_{D} \cdot \sin \alpha,
$$

where

$$
a_{D}=-v^{2} \cdot K, \alpha=\operatorname{arctg} \frac{U}{1500}, v=\frac{V}{3.6}
$$

\subsection{Kinematic excitation of vehicle in the y-axis direction}

The kinematic excitation of the vehicle in the y-axis direction was performed due to the difference of momentaneous rolling radii circles function and wave movement of wheelset with the amplitude of $3 \mathrm{~mm}$ and wavelength $L=8.647 \mathrm{~m}$. The wavelength results from the equivalent conicity function for the given contact couple profiles and the amplitude of $3 \mathrm{~mm}$.

$$
u_{y}=u_{0} \cdot \sin \left(\frac{2 \cdot \pi \cdot x}{L}\right)+\frac{Y_{L}(x)+Y_{P}(x)}{2},
$$

where:

$u_{o}$ - is the aplitude of periodical wheelset movement,

$L$ - is the wavelength of periodical wheelset movement,

$x \quad$ - is the line performed by the wheelset

\subsection{Kinematic excitation in the $\mathrm{z}$-axis direction}

The kinematic excitation of the vehicle system in the z-axis direction is caused by a vehicle running across the measured uneven- ness of rails and the difference in momentaneous rolling circles diameters.

- Right wheels

$$
u_{2}=Z_{P}(x)+\Delta R_{P}(y), y=u_{0} \cdot \sin \left(\frac{2 \cdot \pi \cdot x}{L}\right)
$$

where

$u_{o}$ - is the amplitude of periodical wheelset movement,

$L$ - is the wavelength of periodical wheelset movement,

$x \quad$ - is the line performed by the wheelset

$$
\Delta R_{P}(y, w)=|\Delta R(y, w)| \text { if } y>0
$$
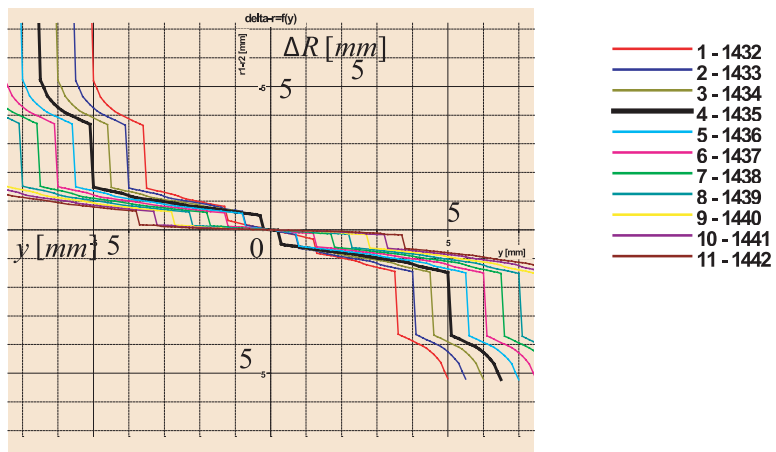

Fig.17 The function for common couple of theoretical profiles (a wheel S1002 and a rail UIC60 with the inclination of 1:40, for various gauge values)

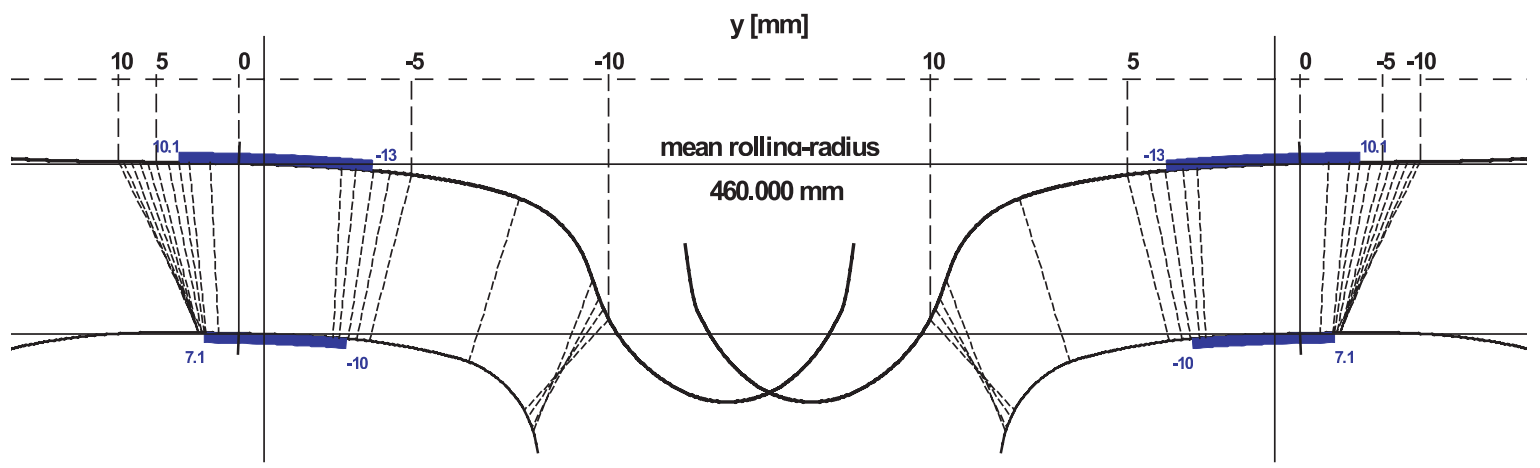

Fig.15 Contact points of S1002/UIC60 profiles couple, for the gauge of $1435 \mathrm{~mm}$

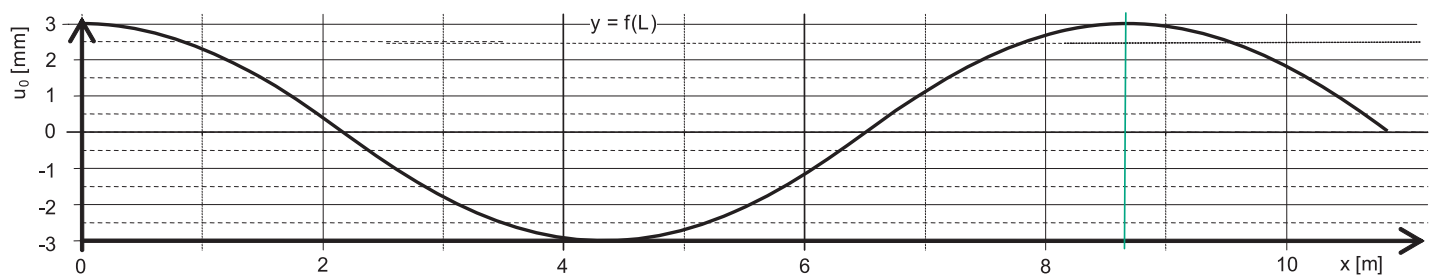

Fig.16 The wavelenght of periodical movement of a wheelset with the amplitude of $3 \mathrm{~mm}$ 
and $\Delta R_{P}(y, w)=0$ if $y<=0$

where the $\Delta R(y, w)$ is the function of differency of momentaneous wheelset wheels rolling circles, computed from the geometrical contact of wheel and rail profiles, $w(x)$ is a track gauge that is evaluated according to the relation (5).

\section{- Left wheels}

$$
u_{s L}=Z_{L}(x)+\Delta R_{L}(y), y=u_{0} \cdot \sin \left(\frac{2 \cdot \pi \cdot x}{L}\right)
$$

where

$u_{o}$ - is the amplitude of periodical wheelset movement,

$L$ - is the wavelength of periodical wheelset movement,

$x \quad$ - is the line performed by the wheelset

$$
\begin{aligned}
& \Delta R_{L}(y, w)=|\Delta R(y, w)| \text { if } y<0 \\
& \text { and } \Delta R_{L}(y, w)=0 \text { if } y>=0
\end{aligned}
$$

where the $\Delta R(y, w)$ is the function of difference of momentaneous wheelset wheels rolling circles computed from the geometrical contact of wheel and rail profiles, $w(x)$ is a track gauge that is evaluated according to the relation (5).

\section{Model verification}

The model was verified with the help of the computed and given characteristic curves comparison. The depencence curves between the forces and strain of springs, or between the forces and velocities in the dampers were "measured" in the nonlinear members of the flexible bindings. The parameters of the given characteristic curves were obtained from the literature [10]:

- a damper of primary suspension (MSC.ADAMS) PVD,

- a damper of wheelset turning (MSC.ADAMS) SYD,

- a damper of secondary suspension (MSC.ADAMS) SVD,

- a transversal damper (MSC.ADAMS) SLD,

- a flexible bump stop (MSC.ADAMS) BS

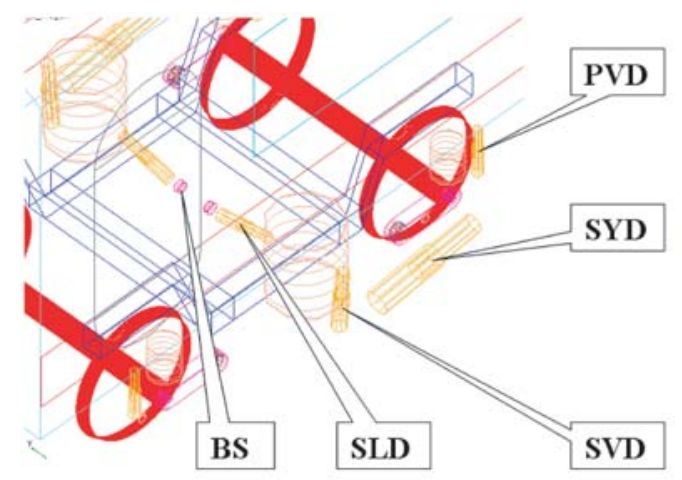

Fig.18 The bogie scheme with flexible bindings
Dampers characteristics [10]

Tab. 2

\begin{tabular}{|c|c|c|c|c|c|c|c|c|}
\hline & \multicolumn{2}{|c|}{ PVD } & \multicolumn{2}{c|}{ SVD } & \multicolumn{2}{c|}{ SYD } & \multicolumn{2}{c|}{ SLD } \\
\hline & $\mathrm{V}$ & $\mathrm{F}$ & $\mathrm{V}$ & $\mathrm{F}$ & $\mathrm{V}$ & $\mathrm{F}$ & $\mathrm{V}$ & $\mathrm{F}$ \\
\hline & {$\left[\mathrm{ms}^{-1}\right]$} & {$[\mathrm{N}]$} & {$\left[\mathrm{ms}^{-1}\right]$} & {$[\mathrm{N}]$} & {$\left[\mathrm{ms}^{-1}\right]$} & {$[\mathrm{N}]$} & {$\left[\mathrm{ms}^{-1}\right]$} & {$[\mathrm{N}]$} \\
\hline 1 & -1.0 & -1000 & -1.0 & -7100 & -1.0 & $-3.97 \mathrm{E} 4$ & -1.0 & -8500 \\
\hline 2 & -0.28 & -400 & -0.26 & -3000 & -0.14 & $-1.1 \mathrm{E} 4$ & -0.305 & -4000 \\
\hline 3 & -0.16 & -300 & $-8.0 \mathrm{E}-2$ & -2000 & -0.11 & $-1.0 \mathrm{E} 4$ & -0.15 & -3000 \\
\hline 4 & $-9.0 \mathrm{E}-2$ & -200 & $-4.0 \mathrm{E}-2$ & -1775 & $-5.5 \mathrm{E}-2$ & -8000 & $-7.0 \mathrm{E}-2$ & -2000 \\
\hline 5 & $-4.0 \mathrm{E}-2$ & -100 & $-1.5 \mathrm{E}-2$ & -1000 & $-4.0 \mathrm{E}-2$ & -7000 & $-3.0 \mathrm{E}-2$ & -1000 \\
\hline 6 & 0.0 & 0 & 0.0 & 0 & 0.0 & 0.0 & 0.0 & 0.0 \\
\hline 7 & $4.0 \mathrm{E}-2$ & 100 & $1.5 \mathrm{E}-2$ & 1000 & $4.0 \mathrm{E}-2$ & 7000 & $3.0 \mathrm{E}-2$ & 1000 \\
\hline 8 & $9.0 \mathrm{E}-2$ & 200 & $4.0 \mathrm{E}-2$ & 2000 & $5.5 \mathrm{E}-2$ & 8000 & $7.0 \mathrm{E}-2$ & 2000 \\
\hline 9 & 0.16 & 300 & $8.0 \mathrm{E}-2$ & 2000 & 0.11 & $1 . \mathrm{E} 4$ & 0.15 & 3000 \\
\hline 10 & 0.28 & 400 & 0.26 & 3000 & 0.14 & $1.1 \mathrm{E} 4$ & 0.305 & 4000 \\
\hline 11 & 1.0 & 1000 & 1.0 & 7100 & 1.0 & $3.97 \mathrm{E} 4$ & 1.0 & 8500 \\
\hline
\end{tabular}

A bump stop characteristic [10]

Tab. 3

\begin{tabular}{|c|c|c|c|c|c|c|c|c|}
\hline \multicolumn{7}{|c|}{ BS } \\
\hline & $\begin{array}{c}\text { Defor- } \\
\text { mation }\end{array}$ & F & $\begin{array}{c}\text { Defor- } \\
\text { mation }\end{array}$ & $F$ & & $\begin{array}{c}\text { Defor- } \\
\text { mation }\end{array}$ & $F$ \\
\hline & {$[\mathrm{m}]$} & {$[\mathrm{N}]$} & & {$[\mathrm{m}]$} & {$[\mathrm{N}]$} & & {$[\mathrm{m}]$} & {$[\mathrm{N}]$} \\
\hline 1 & 0 & 0 & 4 & $1.5 \mathrm{E} 2$ & 3730 & 7 & $3.0 \mathrm{E} 2$ & $1.717 \mathrm{E} 4$ \\
\hline 2 & $5.0 \mathrm{E}-3$ & 600 & 5 & $2.0 \mathrm{E} 2$ & 6870 & 8 & $3.5 \mathrm{E} 2$ & $2.92 \mathrm{E} 4$ \\
\hline 3 & $1.0 \mathrm{E}-2$ & 1760 & 6 & $2.5 \mathrm{E} 2$ & $1.158 \mathrm{E} 4$ & 9 & $4.0 \mathrm{E} 2$ & $2.3 \mathrm{E} 5$ \\
\hline
\end{tabular}

The assessment principle: the forces in nonlinear members were computed as the internal forces in the serial connected linear springs with high stiffness.

The prescribed flexible member characteristics are represented by the curves in the graphs. The linear dependence represents the basic stiffness, or better the basic stiffness constant.

\section{Comfort indexes for a model with nonlinear members}

The computational model with nonlinear members topology shown in the Fig. 21 consists of 80 nodal points and 132 elements. The nodes $67,77,73,80$ and 70 create the left side of the vehicle frame, the nodes $65,22,71,78$ and 88 create the right side of vehicle frame. The vehicle model moves in the direction from the left to the right side. The Tab. 4 represents the list of computed comfort indexes. These indexes were evaluated under the above mentioned conditions. In Fig. 23 and Fig. 24 there are graphical interpretations of indexes valid for the depicted nodes. 


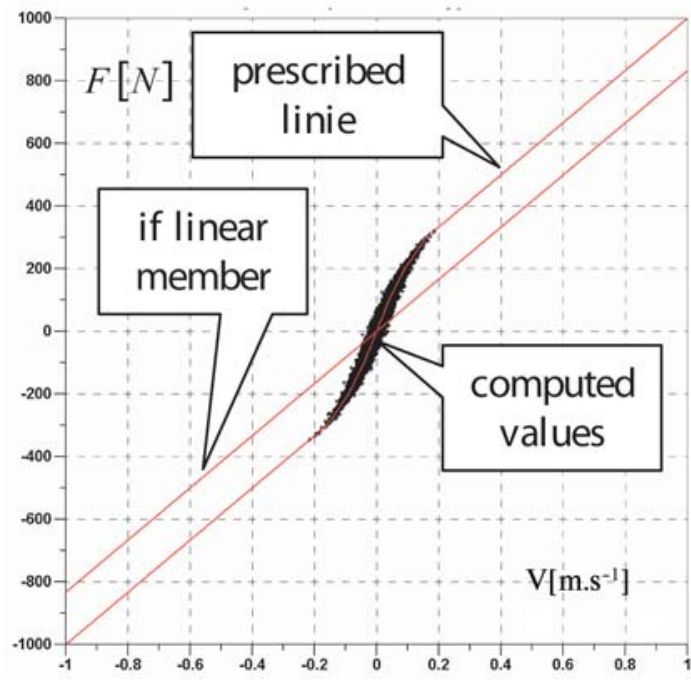

Fig. 19 Forces evaluation in the damper of primary suspension (DELTA)

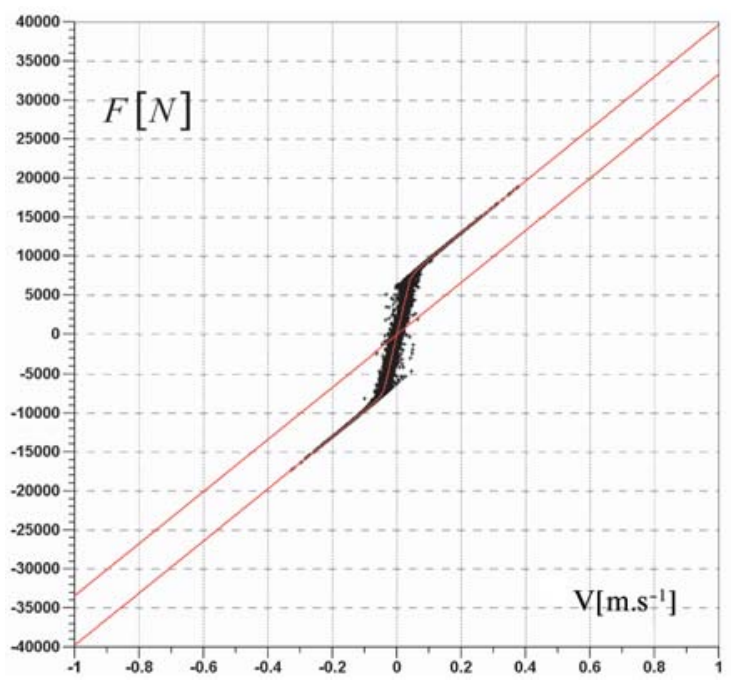

Fig. 20 Forces evaluation in the longitudinal damper (DELTA)

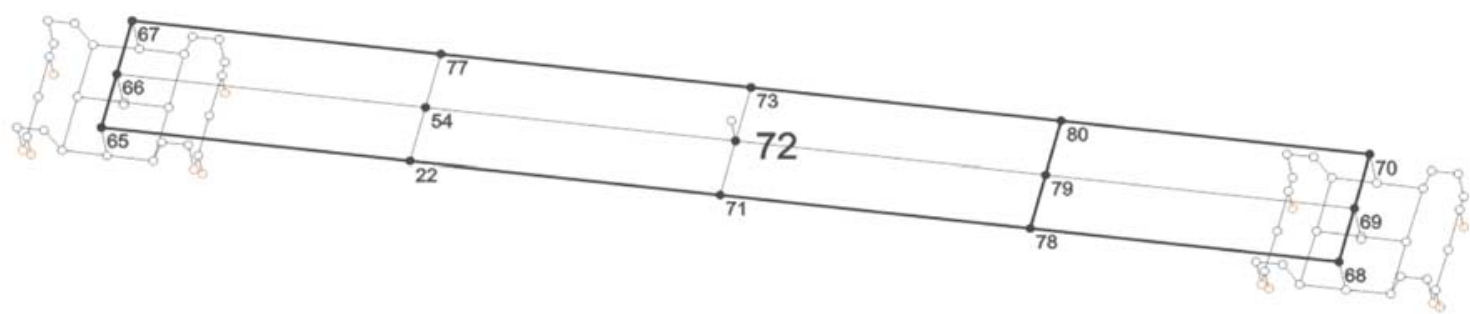

Fig. 21 The node points numbering in the places of indexes evaluation

Passanger comfort indexes for the model with nonlinear members

\begin{tabular}{|c|c|c|c|c|c|c|c|}
\hline & Node & $\begin{array}{c}\text { Index } \\
\text { floor }\end{array}$ & $\begin{array}{c}\text { Index } \\
\text { standing } \\
\text { position }\end{array}$ & Node & $\begin{array}{c}\text { Index } \\
\text { floor }\end{array}$ & $\begin{array}{c}\text { Index } \\
\text { standing } \\
\text { position }\end{array}$ \\
\hline 1 & 65 & 2.319 & 2.205 & 9 & 73 & 1.555 & 1.692 \\
\hline 2 & 66 & 2.069 & 2.18 & 10 & 78 & 1.895 & 2.038 \\
\hline 3 & 67 & 2.279 & 2.207 & 11 & 79 & 1.734 & 2.012 \\
\hline 4 & 22 & 1.707 & 1.763 & 12 & 80 & 1.872 & 2.04 \\
\hline 5 & 54 & 1.522 & 1.709 & 13 & 68 & 2.674 & 2.74 \\
\hline 6 & 77 & 1.692 & 1.737 & 14 & 69 & 2.49 & 2.716 \\
\hline 7 & 71 & 1.531 & 1.691 & 15 & 70 & 2.662 & 2.742 \\
\hline 8 & 72 & 1.367 & 1.662 & & & & \\
\hline
\end{tabular}

Tab. 4
9. Conclusion

A vehicles dynamics properties analysis is a very wide field. We can process this issue form various points of view. We put our attention in the accelerations calculation. These accelerations input into the relations for passenger ride comfort assessment. The accelerations are commonly measured in the given places of a vehicle body when the vehicle is running. They are filtered, weighted in accordance with the European standards ENV 12999:1999 or prENV 12999:2006 before processing for the comfort indexes evaluation $[1,12]$. The accelerations in question can be obtained with the help of a simulation computation [5] as well. The method of mathematical model computation, vehicle parameters and boundary conditions are of great importance for results (accelerations) trustworthiness. In the paper we described one proposal or idea of possible verification of a computational nonlinear model based on a strictly given mechanical system excitation which comes out from real track data. The final accelerations as the vehicle model response from excitation were used as input parameters for the common comfort index evaluation due to the above mentioned European standard. 


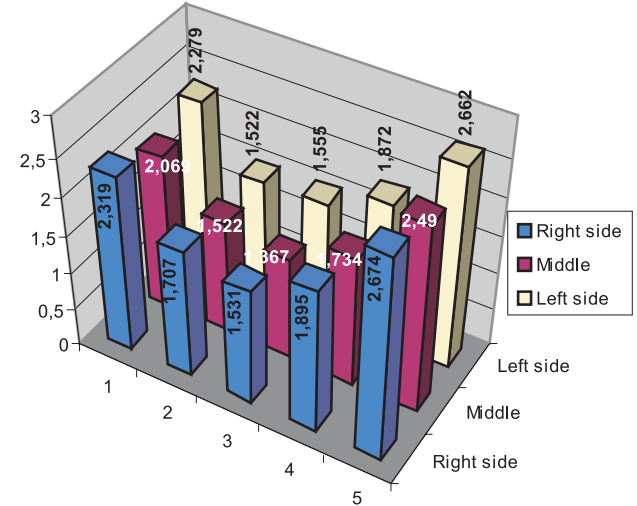

Fig. 22 Comfort for passengers for a floor evaluation, when the vehicle model has nonlinear members

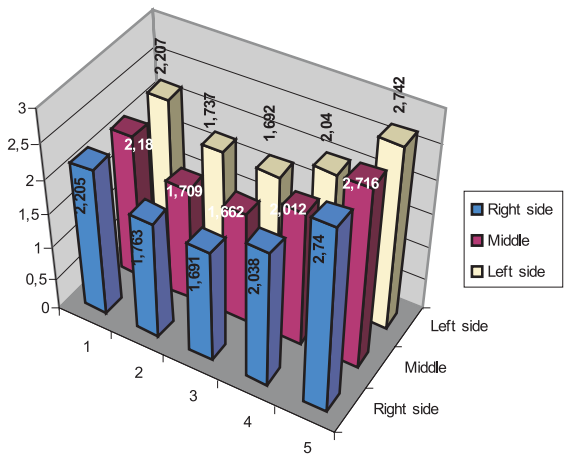

Fig. 23 Comfort for passengers for a standing position evaluation, when the vehicle model has nonlinear members

\section{Acknowledgement}

The work was supported by the Scientific Grant Agency of the Ministry of Education of the Slovak Republic and the Slovak Academy of Sciences in the project No. 1/3169/06 "Properties
Research of Rail Vehicles in Movement with Emphasis on the Solution of a Wheel and Rail Contact at the Wheelset Rolling in the Rail via Computer Simulation" and in the project No. 1/4119/07: "Investigation of a dynamical properties of a vehicle".

\section{References}

[1] ENV 12299: 1999E Railway Applications - Ride Comfort for Passengers - Measurement and Evaluation, European Prestandard, February 1999.

[2] GERLICI, J., LACK, T.: Methods for Vehicle Vibration Analysis in Time Domain, Prace naukowe Politechniki Warszawskiej, Z. 63 , Transport, 2007, pp. 71-81. Publishing House of the Warsaw University of Technology, ISSN 1230-9265, Warszawa 2007.

[3] GERLICI, J., LACK, T.: Survey of Ride Comfort for Passengers (in Slovak), Acta Mechanica Slovaca, Kosice 4-B/2006, pp. 155-162, Optimization of Mechanical Systems, vol. 10, ISSN 1335-2393, Kosice, 2006.

[4] GERLICI, J., LACK, T., ONDROVA, Z.: Evaluation of Comfort for Passengers of Railway Vehicles. Communications - Scientific Letters of the University of Zilina, 4/2007, pp. 44-49, ISSN 1335-4205, EDIS - Publishing house of University of Zilina, 2007.

[5] LACK, T.: The Dynamic Properties Analysis of Vehicles from the Point of View of Ride Comfort (in Slovak), Habilitation Work, pp. 176, Faculty of Mechanical Engineering University of Zilina, 2007.

[6] LACK, T., GERLICI, J.: Vehicles Dynamical Properties Analysis from the Point of View of Comfort for Passengers, Archives of Transport, 1-2/2007, pp. 91-110, ISSN 8066-9546, Warszawa 2007.

[7] LACK, T., GERLICI, J.: The Programme System DELTA Exploitation for Numerical Analysis Performances (in Slovak), Proc. of 18th International Conference "Current Problems in Rail Vehicles - PRORAIL 2007" - Part II., pp. 11 22, EDIS, ISBN 978-80-8927607-3, Zilina, 2007.

[8] LACK, T., GERLICI, J., HLAVNA, V.: Evaluation of Ride Comfort for Passengers, pp. 9-13, Horizonty dopravy, ISSN 1210-0978, 5/2006, Special Edition, Transport Research Institute, Zilina 2006.

[9] LACK, T., GERLICI, J., HLAVNA, V.: The Vehicle Comfort, Case study, Maintenance and Reliability 2006, ISSN 1507-2711, 4(32)/2006, pp. 89-91, Polskie Naukowo-Techniczne Towarysztwo Eksploatacyjne Warszawa, 2006.

[10] MSC.ADAMS/Rail: A Model of ERRI Coach Wagon for Programme System Verification.

[11] POLACH, O.: Rail Vehicles Analysis, Transport Means - Computational Methods, Textbook, University of Zilina, ISBN 80-8070476-7, EDIS-Publishing house of University of Zilina, 2005.

[12] prENV 12299: 2006 Bahanwendungen - Fahrkomfort für Fahrgäste - Messung und Auswertung, 2006. 